\title{
COVID-19 Associated Pneumonia Overview of Real Time Cases
}

\author{
Muhammad Farhan Saeed* \\ Department of Environmental Sciences, COMSATS University Islamabad, Vehari Campus, \\ Vehari, Pakistan \\ *Corresponding Author: Muhammad Farhan Saeed, Department of Environmental \\ Sciences, COMSATS University Islamabad, Vehari Campus, Vehari, Pakistan.
}

Received: March 25, 2020

Published: April 13, 2020

(C) All rights are reserved by Muhammad

Farhan Saeed.
Coronavirus disease (COVID-19) is a newly spread disease started in China and spreading in all over the world. Infected people with the COVID-19 virus experiencing varying levels of respiratory illness and recover without requiring special treatment. People with older age group generally (over 50 years), and people with medical problems like heart diseases, diabetes, respiratory disease, and are vulnerable to serious illness by this virus exposure. Regalado, 2020 had described three basic and possible measures to stop the Covid-19 disease epidemic. (1) Extraordinary restrictions on free movement and assembly, as well as aggressive testing, this option seems impossible now that the virus is in over 100 countries. (2) Development of vaccine which needs time to make it successful, (3) A third is potentially effective but horrible to consider; the spread of virus, eventually the virus will spread all over and people will have been infected and (if they survive) become immune that the outbreak will bust on its own and harder to find a susceptible host. This phenomenon is known as herd immunity. If this happened, it has potential to infect $60 \%$ of the world population in a spam of one year.

The data from Worldometer, 2020 indicates that population of younger individuals has low infection rate (Figure 1) and are potentially developing resistance very fast compared to older population, the possible reason is because the immune system of older population are not ready or stronger to respond this virus. Moreover, the male populations have higher rate of infection (Figure 2) possibly due to the more out-door activities make them at higher risk of contaminations. In addition, the Worldometer, 2020 depict heart patients are more susceptible toward COVID-19 infestations, approximately $>12 \%$ death cases have been confirmed, similarly population with health problems of diabetes, respiratory diseases, hypertension and cancer are highly vulnerable to COVID-19 infestations that is resulting ultimate deaths (Figure 3) [1].

I believe that the possible hypothesis of herd immunity will take hold in case of current COVID-19 epidemic because of the mode of fast spread and populations all over the world will become resistant as this happened in nature with other germs when people get infected, recovered and sustained the resistance, because their immune system developed antibodies. The data clearly expedite that about 80,000 people have recovered from the coronavirus already indicating likely they are now resistant and there are cases reported in media news that people have been reported with positive COVID-19 test however did not show the symptoms. According to

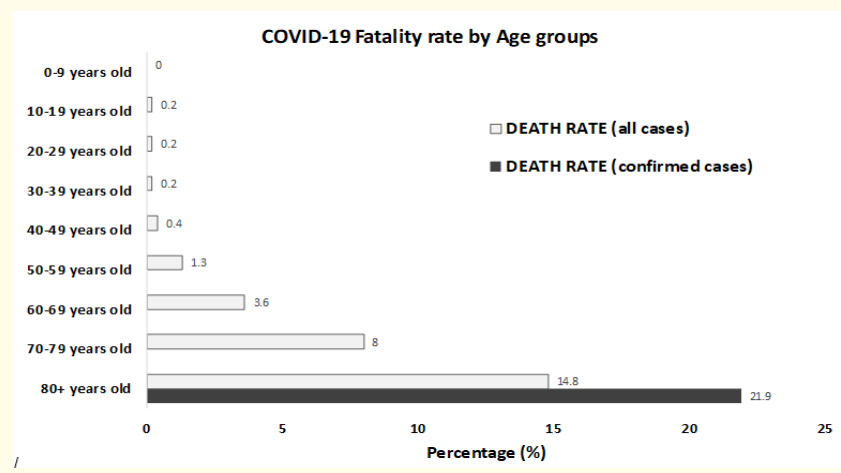

Figure 1: Age of Coronavirus Deaths. Death Rate = (number of deaths/number of cases) = probability of dying if infected by the virus (\%). This probability differs depending on the age group. The percentages shown below do not have to add up to $100 \%$, as they do NOT represent share of deaths by age group. Rather, it represents, for a person in a given age group, the risk of dying if infected with COVID-19 (Data source: Worldometer, 2020).

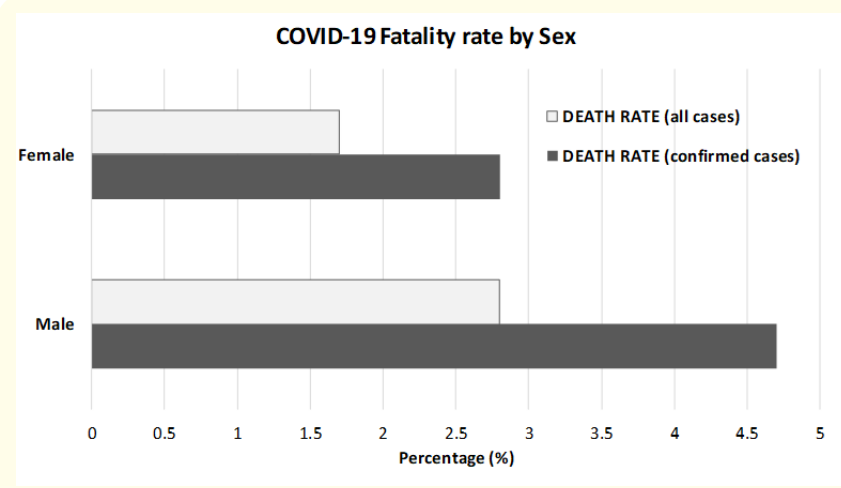

Figure 2: Sex ratio of Coronavirus. Death Rate $=$ (number of deaths/number of cases) = probability of dying if infected by the virus (\%). This probability differs depending on sex. When reading these numbers, it must be taken into account that smoking is much more prevalent among males. Smoking increases the risks of respiratory complications The percentages do not have to add up to $100 \%$, as they do NOT represent share of deaths by sex (Data source: Worldometer, 2020).

the Marc Lipsitch COVID-19 rate of spread is higher than the ordinary flu, but similar to that of novel emergent influenzas that have occasionally swept the globe before. "That is similar to pandemic flu of 1918, and it implies that the end of this epidemic is going to 


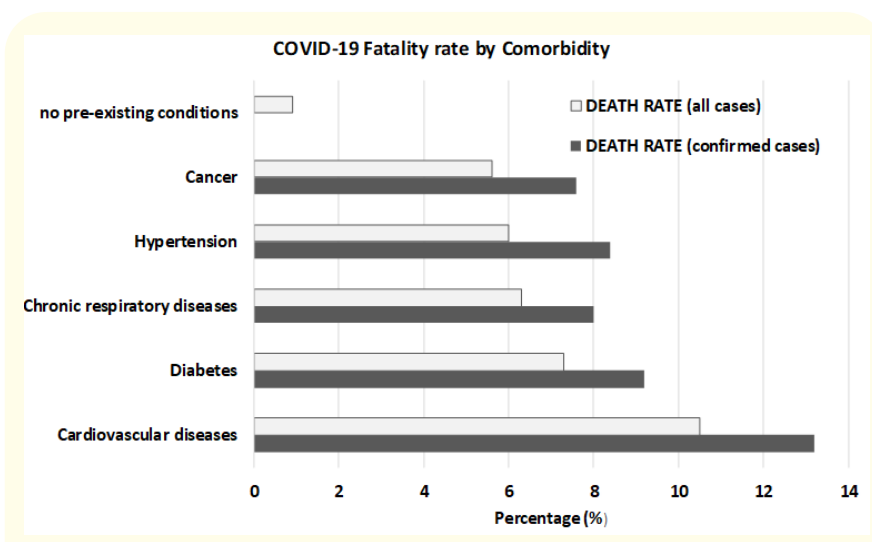

Figure 3: Patients who reported no pre-existing ("comorbid") medical conditions had a case fatality rate of $0.9 \%$. Pre-existing illnesses that put patients at higher risk of dying from a COVID-19 infection are: Death Rate $=$ (number of deaths $/$ number of cases) $=$ probability of dying if infected by the virus (\%). This probability differs depending on pre-existing condition. The percentage shown below does NOT represent in any way the share of deaths by preexisting condition. Rather, it represents, for a patient with a given pre-existing condition, the risk of dying if infected by COVID-19. The percentages do not have to add up to $100 \%$, as they do NOT represent share of deaths by condition (Data source: Worldometer, 2020).

require nearly $50 \%$ of the population to be immune, either from a vaccine, which is not on the immediate horizon, or from natural infection" [2].

If a healthy individual expose to a COVID-19 infected person for logger time and he is not resistant and his immune system is not ready it could make him sick suddenly. It can also be anticipated that this virus shows symptoms after 14 days [1]. It could be predictable that when a specific population of virus in a body complete or complete its cycle, it will be ready to hit the immune system to show up illness symptoms, this mechanism of infection is very similar and likewise Malarial infection therefore the logical fact confirms this hypothetical point that hydroxychloroquine/ chloroquine a malaria drug is being very effective to control this virus [3]. It is possible hydroxychloroquine or chloroquine is not/ or may be CONID-19 control drug because till now there is no scientific confirmation available but factors indicates that this drug is helpful to treat the COVID-19 infected patients possibly that boostup the immune system and gives the patient body time to recover by producing antibodies very quickly, there is other fact seems true that older people immune systems could not respond so quickly to establish defense against this virus but it can be assumed the preventive doses of this drug can be helpful [3]. However, in contrast, there is another point that if a healthy individual expose to a COVID-19 by indirectly for example through air or any other means and got very minute exposure and very low germs population/ weakened or killed forms that could act as natural vaccine to develop antibodies so that individual's immune system got alerted to germs, this could be predicted from the data of Worldometer,
2020 which indicate that the recovering rate of CONID-19 patients is higher.

I believe, concept herd immunity is going to be very much correct in coronavirus epidemic, the whole population of the world will get COVID-19 because of its mode of environmental spread and population will be resistant over the time, here the most important is that, the less exposure of susceptible population can be saved by only reducing exposure to infected people. If the infection exposure is higher from carriers, the non-carriers body immune system cannot respond so fast to this specific virus to resist [4-6].

I hypothesize that whole world will have coronavirus sooner or later, however, there are three possible ways to reduce infestations and potentially develop the herd immunity:

1. There is urgent need to adopt some measure to separate the old age people from younger

2. Avoid sudden exposure with infected people to keep yourself at social distance by isolating yourself.

3. There are reports that COVID-19 has air-borne mode of spread therefore there is possibility that if minimal exposure to germs happened, the body will develop immunity in a spatial and temporal mode in the world populations.

\section{Bibliography}

1. Worldometer. "Coronavirus Age, Sex, Demographics (COVID-19)” (2020).

2. Marc Lipsitch (Harvard University epidemiologist) A Coordinated Boston Response to COVID19" (2020).

3. Tim Smith and Tony Prosser. "COVID-19 Drug Therapy - Potential Options Pharm D Clinical Drug Information”. Clinical Solutions (2020).

4. Feuer Berkeley Lovelace Jr and Noah Higgins-Dunn William. "WHO Considers 'airborne Precautions' for Medical Staff after Study Shows Coronavirus Can Survive in Air". CNBC (2020).

5. The Epidemiological Characteristics of an Outbreak of 2019 Novel Coronavirus Diseases (COVID-19) - China CCDC (2020).

6. "Report of the WHO-China Joint Mission on Coronavirus Disease 2019 (COVID-19)". World Health Organization (2020).

\section{Assets from publication with us}

- Prompt Acknowledgement after receiving the article

- Thorough Double blinded peer review

- Rapid Publication

- Issue of Publication Certificate

- High visibility of your Published work

Website: https://www.actascientific.com/

Submit Article: https://www.actascientific.com/submission.php Email us: editor@actascientific.com

Contact us: +919182824667 